\title{
Morinda citrifolia Linn. (Noni) fruit extract attenuates ethanol seeking behavior in mouse runway paradigm
}

\author{
Yasmin KHAN 1, 2* (D), Vijayapandi PANDY 1,3* (D) \\ 1 Department of Pharmacology, Faculty of Medicine, University of Malaya, 50603 Kuala Lumpur, Malaysia. \\ 2 Department of Pharmacy, Benazir Shaheed University Lyari, Karachi, Pakistan. \\ 3 Department of Pharmacology, Chalapathi Institute of Pharmaceutical Sciences, Chalapathi Nagar, Lam, Guntur- \\ 522034, Andhra Pradesh, India. \\ * Corresponding Authors. E-mail: yasminkhanmpharm@gmail.com (Y.K.); Tel. +92-302-220 25 62. E-mail: \\ pandiphd@gmail.com (V.P.); Tel. +91-863-252 4124.
}

Received: 27 April 2020 / Revised: 28 June 2020 / Accepted: 21 August 2020

\begin{abstract}
In this study, we used methanolic extract of Morinda citrifolia Linn. fruit (MMC) in order to find its effect against ethanol seeking behavior in a modified mouse runway paradigm. During conditioning/acquisition animals were treated with accelerated doses of ethanol $(0.5-4 \mathrm{~g} / \mathrm{kg}$, i.p.) for 5 days (Day 1- Day 5). Then, ethanol seeking behavior was assessed on Day 6 (postconditioning test). Ethanol seeking behavior was confirmed in ethanol control group in which the run time to reach the target box was significantly decreased. The test drug $\mathrm{MMC}(1,3$, and $5 \mathrm{~g} / \mathrm{kg}$, p.o.) caused a significant reversal of the ethanol seeking behavior by increasing the run time to reach the goal box as seen with the reference drug acamprosate (ACAM; $300 \mathrm{mg} / \mathrm{kg}$, p.o.) in mice. After postconditioning test, nonrewarded abolishment assays were performed for a period of five days (Day 7 -Day 11). After 5 days of abolishment (abstinence), a priming dose of ethanol (the highest dose at $1 / 5$ th portion applied in control (i.e. $0.8 \mathrm{~g} / \mathrm{kg}$, i.p.)) in house cage significantly reinstated the ethanol-seeking behavior. Interestingly, MMC at a higher dose $(5 \mathrm{~g} / \mathrm{kg}$, p.o.) showed significant halt on ethanol-induced reinstatement in mice as shown with the reference drug ACAM (300 $\mathrm{mg} / \mathrm{kg}$, p.o.). The outcome of this study reveals that MMC alleviated ethanol seeking behaviour in modified mouse runway paradigm and it could be effectively used to treat alcohol dependence.
\end{abstract}

KEYWORDS: Alcohol dependence; acamprosate; Morinda citrifolia Linn; mouse runway paradigm; selfadministration.

\section{INTRODUCTION}

The motivational effects of numerous consummatory reinforcers including food, water and drugs of abuse have been extensively studied using a test on alley running performance in rodents [1]. Traditional runway models of operant drug reward have been restricted by systematization aspects related to the requirement to ensure medicament delivery to the animal over heavy distances beside intervening with the runway behavior of rats [2]. Ideally, one would want a system with precise motivational and confounding factors that should not affect animal behavior. Recently, we developed a novel runway model of drug selfadministration using mice without compromising a great active long-term analysis of runway efficient performance for drug reward [3].

Morinda citrifolia Linn. (Noni) has been utilized as diet source, medicine, and fabric dyes by Polynesian people [4]. Traditionally, M. citrifolia has been widely used as prophylaxis and treatment of many CNS disorders such as anxiety, depression, psychosis and drug dependence. In earlier study by our research group, MMC was reported for anxiolytic and antidepressant-like activity [5] anti-psychotic-like activity [6] and anticraving effect in opposition to heroin, ethanol and methamphetamine dependence using conditioned place preference test in rats and mice [7-10]. The current investigation was designed to test the activity of MMC against ethanol seeking behavior in mice by employing modified runway paradigm of selfadministration of drug.

How to cite this article: Khan Y, Pandy V. Morinda citrifolia Linn. (Noni) fruit extract attenuates ethanol seeking behavior in mouse runway paradigm. J Res Pharm. 2020; 24(5): 632-639. 


\section{RESULTS}

\subsection{Inhibitory effect of MMC and ACAM against ethanol seeking in mice by employing the modified} runway paradigm of drug self-administration

Figure 1 narrates the operating period of pre- as well as post-conditioning of the different treatment groups. The two-way ANOVA manifested the effect of treatment $[\mathrm{F}(5,84)=10.81 ; \mathrm{P}<0.0001]$ and Treatment $\times$ Time interaction $[\mathrm{F}(5,84)=16.94 ; \mathrm{P}<0.0001]$ in a significant manner. However, a non-significant effect of Time $[F(1,84)=3.754 ; \mathrm{P}=0.0561]$ was observed. The Post doc Bonferroni's multiple comparisons test revealed that there was no significant difference between all treatment groups on pre-conditioning run times. However, the post conditioning run times were significantly different between groups (P<0.0001 for Ethanol control versus Saline control; P<0.05 for MMC 1g versus Ethanol control; P<0.0001 for MMC $3 g$ and MMC 5g versus Ethanol control; $\mathrm{P}<0.001$ for ACAM versus Ethanol control). This results demonstrated a go down in runtime $(\mathrm{s})(\mathrm{P}<0.0001)$ for ethanol control when compared with saline control group which one assumes the ethanol seeking behaviour in ethanol-conditioned mice. Interestingly, the MMC (1, 3 and 5 $\mathrm{g} / \mathrm{kg}$, p.o.) treated groups presented a significant $(\mathrm{P}<0.05)$ reversal of the ethanol seeking behaviour in mice as is seen with the reference drug acamprosate $(300 \mathrm{mg} / \mathrm{kg}$, p.o.) treated mice (Figure 1).

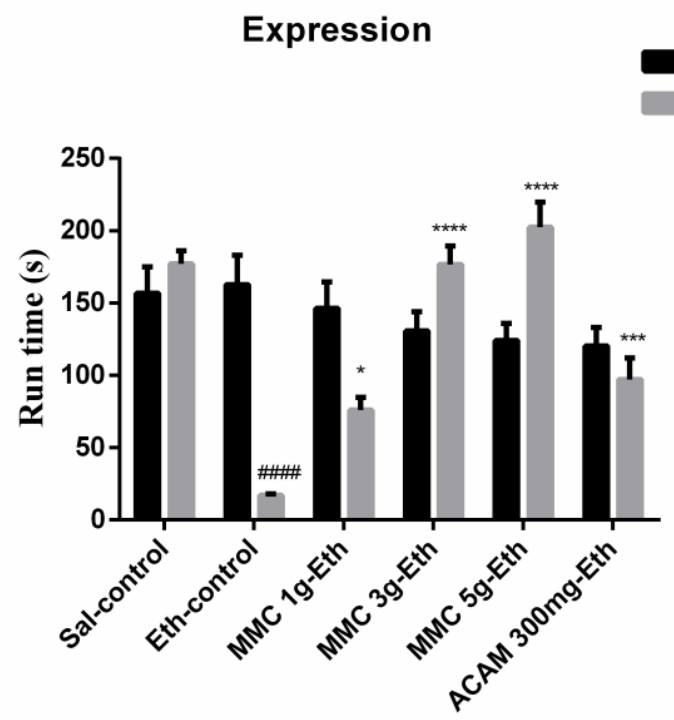

Figure 1. Effect of MMC and ACAM on expression of ethanol run times (mean \pm SEM; $n=7-9$ ) in mice using a runway paradigm. Significant differences were observed at \#\#\#\#p<0.0001 when compared with the saline control group; ${ }^{*} \mathrm{p}<0.05,{ }^{* * *} \mathrm{p}<0.001$ and ${ }^{* * * *} \mathrm{p}<0.0001$ when compared with the ethanol control group; when not indicated, the differences were not statistically significant.

Furthermore, the motivation of the test group to approach the desired box during termination attempts (Ext 1 to Ext 5) from Day 7 to Day 11 were compared between different treatment groups (saline control, ethanol control, MMC (1, 3, and $5 \mathrm{~g} / \mathrm{kg}$, p.o.) along with ACAM (300 mg/kg, p.o.)) as shown in (Figure 2). The repeated measures ANOVA revealed a significant effect of treatment $[\mathrm{F}(5,210)=54.69 ; \mathrm{P}<$ $0.0001]$ and Treatment×Time interaction $[\mathrm{F}(20,210)=2.711 ; \mathrm{P}=0.0002]$ on runtime. Post hoc analyses on extinction runtime $(\mathrm{s})$ data demonstrated a significant $(\mathrm{p}<0.05)$ decrease in runtime $(\mathrm{s})$ over 5 -day extinction trials for ethanol control group when related with the saline control group that assumes the ethanol seeking behaviour in ethanol-extinct animals upto 5 days. The MMC ( 3 and $5 \mathrm{~g} / \mathrm{kg}$, p.o.) treated groups significantly $(\mathrm{P}<0.001)$ reversed the ethanol seeking behaviour in ethanol-extinct mice as is seen with the reference drug acamprosate $(300 \mathrm{mg} / \mathrm{kg}$, p.o.) treated mice. Albeit, MMC at a concentration of $1 \mathrm{~g} / \mathrm{kg}$, p.o. failed to attenuate the ethanol seeking motivation in ethanol-extinct animals (Figure 2). 


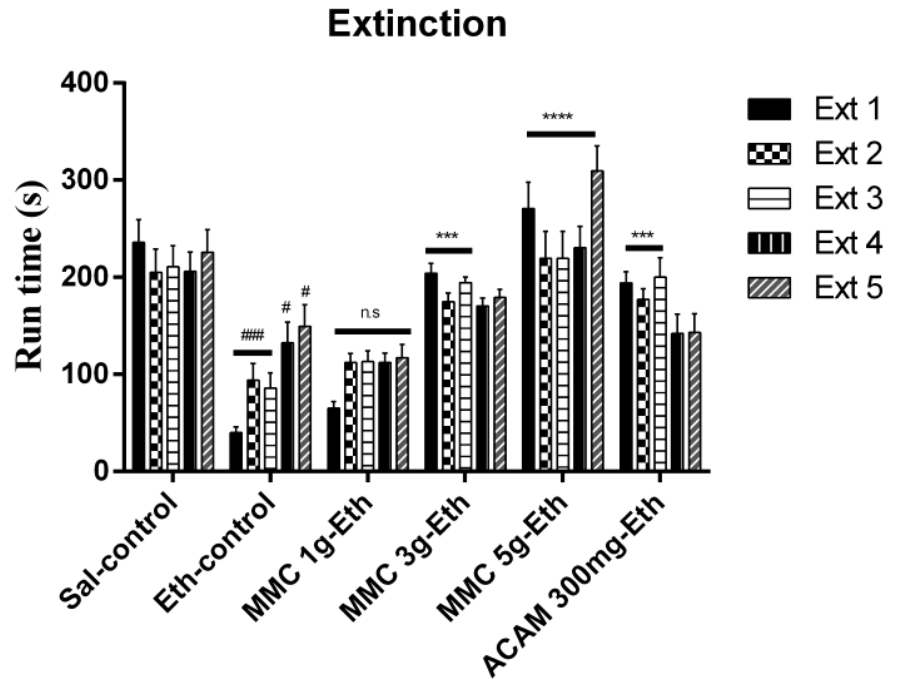

Figure 2. Effect of MMC and ACAM on extinction of ethanol run times (mean \pm SEM; $n=7$ - 9) in mice using a runway paradigm. Significant differences were noted at $\# p<0.05$ and \#\#\#\#p<0.0001 when compared with saline control group; ${ }^{* * *} \mathrm{p}<0.001$ and ${ }^{* * * *} \mathrm{p}<0.0001$ when compared with the ethanol control group; when not indicated, the differences were not statistically significant.

On reinstatement day (Day 13), the two-way ANOVA results indicated a significant change due to Treatment $[\mathrm{F}(5,84)=27.65 ; \mathrm{P}<0.0001]$, Time $[\mathrm{F}(1,84)=26.78 ; \mathrm{P}<0.0001]$ and Treatment $\times$ Time interaction $[\mathrm{F}(5,84)=12.50 ; \mathrm{P}<0.0001]$. The Post doc Bonferroni's multiple comparisons test revealed that the ethanol at a low dose (priming dose $0.8 \mathrm{~g} / \mathrm{kg}$, i.p.) reinstated the ethanol seeking behavior by exhibiting a quicker run time in the ethanol control group (Figure 3). MMC at a higher dose $(5 \mathrm{~g} / \mathrm{kg}$, p.o.) exhibited a significant reversal of the priming ethanol-induced reinstatement in mice that was comparable with the reference drug, acamprosate $(300 \mathrm{mg} / \mathrm{kg}$, p.o.). However, MMC at tested doses of 1 and $3 \mathrm{~g} / \mathrm{kg}$, p.o. failed to reverse the priming ethanol-induced reinstatement in mice.

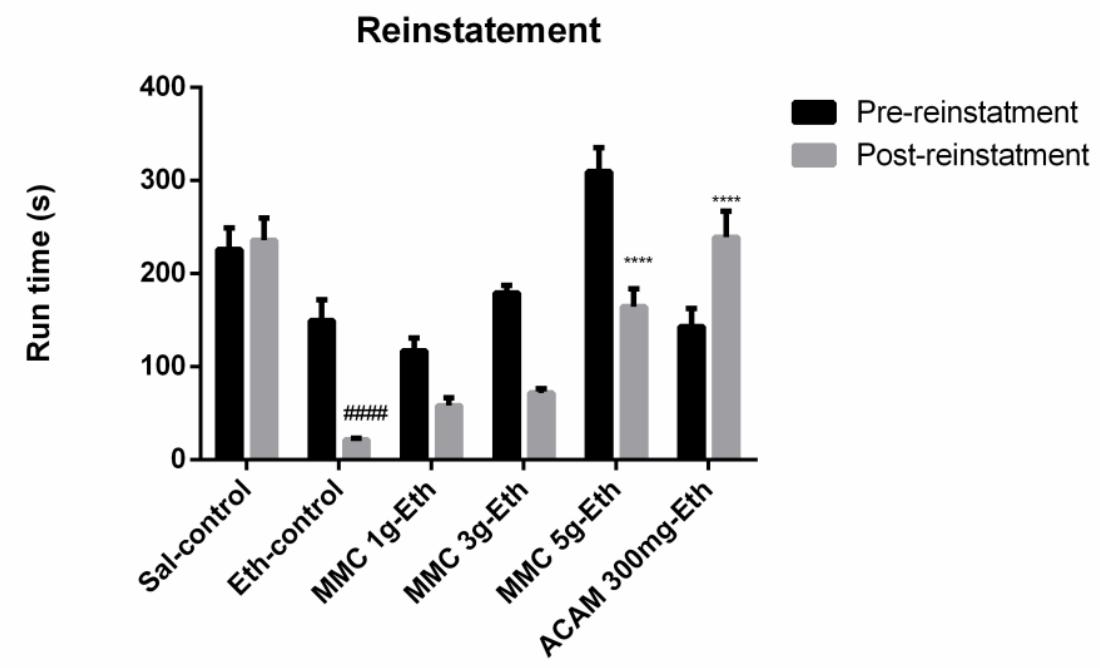

Figure 3. Effect of MMC and ACAM on reinstatement of ethanol run times (mean \pm SEM; $n=7-9$ ) in mice

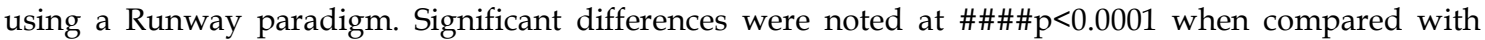
saline control group; ${ }^{* * * *} \mathrm{p}<0.0001$ when compared with the ethanol control group; when not indicated, the differences were not statistically significant. 


\section{DISCUSSION}

Issell et al., (2008) performed a pharmacokinetic study of Morinda citrifolia Linn. (noni) fruit extract in healthy human volunteers. In this study, scopoletin was used as a biomarker for M. citrifolia fruit extract and its plasma concentration were noted in a range of $(0.5$ to $5 \mathrm{ng} / \mathrm{mL}$; upto $8 \mathrm{~h})$ after ingestion of $M$. citrifolia fruit extract capsules (1.5, 2 and 2.5g). This study highlighted scopoletin can be used as a biomarker for pharmacokinetic studies of noni products [11]. Similarly in a preclinical study, Noni puree $(1 \mathrm{ml} / 100 \mathrm{~g}$ b.wt, p.o) was given to female rats and plasma scopoletin level was monitered. This results revealed a peak level of scopoletin was reached in $2 \mathrm{~h}$ and reduced to $50 \%$ in $4 \mathrm{~h} \mathrm{[12].} \mathrm{Moreover,} \mathrm{in} \mathrm{an} \mathrm{in} \mathrm{vitro} \mathrm{study} \mathrm{by} \mathrm{Yang} \mathrm{et} \mathrm{al.,}$ 2015, twelve coumarins including scopoletin was investigated for its ability to penetrate the blood brain barrier (BBB) using MDCK-pHaMDR cell monolayer BBB model. In this study, $\mathrm{P}_{\text {app }}$ value was determined and compared between different coumarins. In general, if $P_{\text {app }}$ value of a drug is more than $1 \times 10^{-5} \mathrm{~cm} / \mathrm{s}$, the drug is expected to have good penetration through BBB. The $\mathrm{P}_{\text {app }}$ AP-BL value of scopoletin was found to be $37.10 \pm 1.97 \times 10^{-6} \mathrm{~cm} / \mathrm{s}$ that was comparable with the reference drug caffeine $\left(43.58 \pm 4.86 \times 10^{-6}\right.$ $\mathrm{cm} / \mathrm{s})$. This study clearly indicated the high penetrating nature of scopoletin through BBB [13].

Zulissetiana and Susilawati (2013) demonstrated that methanolic extract of M. citrifolia fruit (50-800 $\mathrm{mg} / \mathrm{kg}$, p.o.) significantly increased the Brain-derived neurotrophic factor (BDNF) level in the immobilization stressed ( $2 \mathrm{~h}$ immobilization for 21 days) male swiss webster mice [14]. Muralidharan et al. (2010) reported that ethyl acetate extract of $M$. citrifolia fruit $(200,400 \mathrm{mg} / \mathrm{kg}$, for 21 days, p.o.) showed a memory enhancing activity in beta-amyloid (25-35) peptide-induced amnestic mice using step-down inhibitory avoidance, Morris water maze and $\mathrm{Y}$ maze tests [15]. Moreover, this study highlighted the inhibitory effect of ethyl acetate extract of $M$. citrifolia fruit on acetylcholine esterase (AchE) and monoamine oxidase-A (MAO-A) enzymes activity in the brain [15]. Meanwhile, the antioxidant enzymes such as superoxide dismutase (SOD), glutathione reductase (GSHr) and glutathione peroxidase (GSHx) in the mouse brain was significantly reduced in beta-amyloid (25-35) peptide-induced amnestic mice and these enzymes levels were restored in M. citrifolia fruit extract treated mice [15]. All these preclinical study evidences confirm that the biactive principles of $M$. citrifolia fruit extract could penetrate the BBB and can exhibit various CNS activities.

Conditioning with intensifying concentrations of ethanol, $(0.5,1,2,4$ and $4 \mathrm{~g} / \mathrm{kg}$, i.p.) from 1 to 5 days revealed ethanol seeking behavior on postconditioning day (Day 6) by declining the runtime to reach the goal box is explained in Figure 1. This result demonstrated the strong rewarding properties of ethanol that can activate the brain's reward pathways thereby execute motivational ethanol seeking behavior [16]. Interestingly, Figure 1 also demonstrated that the test groups who were treated with $(1,3$ and $5 \mathrm{~g} / \mathrm{kg}$, p.o.) doses of MMC and $(300 \mathrm{mg} / \mathrm{kg}$, p.o.) of ACAM implied the inhibitory activity against ethanol seeking in a modified straight alley runway model. As per literature, dopamine is inferred in certain effective physiological and pharmacological actions including the motivational reward [17]. The dopaminergic neuronal system involving certain brain part for example, the amygdala, the ventral tegmentum and nucleus accumbens, are associated with positive reinforcement, craving of drug and sensitive to recur of ethanol and also some abusable drugs $[18,19]$. The research team of this study earlier reported antidopaminergic activity of MMC following both in vivo and ex vivo investigations [20,6]. Interestingly, our research team also demonstrated the biphasic effect of ethyl acetate fraction of the methanolic extract of unripe noni (M. citrifolia Linn.) fruit (EAMMC) on the dopaminergic system in mice [21]. EAMMC at lower doses $(<25 \mathrm{mg} / \mathrm{kg}$, p.o.) was found to attenuate a dopamine receptor agonist apomorphine-induced cage climbing and methamphetamne-induced stereotypy in mice. On converse, EAMMC at a higher dose $(3000 \mathrm{mg} / \mathrm{kg}$, p.o.) inhibited a dopamine D2 receptor antagonist haloperidol $(0.5 \mathrm{mg} / \mathrm{kg}$, i.p.)-induced catalepsy in mice. This study postulated the blockade of postsynaptic dopaminergic D2 receptors at lower doses of EA-MMC and blockade of presynaptic autodopaminergic D2 receptors (attenuating negative feedback mechanism) at higher doses of EA-MMC could be responsible for the biphasic effect of noni fruit extract [21]

Moreover, it has been proposed the inclusion of phytochemicals of $M$. citrifolia fruit, rutin and scopoletin for its antidopaminergic property [21,22]. Thus, we postulate that the anti-motivational property of MMC against ethanol self-administration in the mouse modified runway paradigm may stem from its antidopaminergic activity. The phytochemicals of noni, rutin and scopoletin might be responsible to have anti-motivational property of MMC against ethanol self-administration. Currently in our laboratory, we directed our investigation applying rutin and scopoletin per se against ethanol seeking behavior in mouse behavioral models. 
Reinforcing/motivational properties of drugs of abuse can be affected by conditioned sensitization of drugs of abuse. In this scenario, the animals might run fast over trials due to formation of conditioned sensitization [23]. However, the notion that conditioned sensitization can be influenced by other parameters like locomotion and cognitive function. Interestingly, MMC was found not to alter spontaneous locomotor activity and also to facilitate learning and memory in mice [9]. Therefore, it is unlikely that the effect of MMC in reversing ethanol self-administration is reponsible for drug-triggered variations in the test animal motoric activity.

In the current protocol, no saline injections were administered in place of the ethanol injections during extinction period since, doing so would undoubtedly have required many more extinction trials to weaken the runway behavior (i.e. the injection itself would be expected to serve as a form of conditioned reinforcement due to its pairing with the administration of the drug). Numerous reports following this protocol have been published in the literature [24-26]. The anti-motivational property of MMC (3 and 5 $\mathrm{g} / \mathrm{kg}$, p.o.) against ethanol seeking was also observed during the extinction period proposing its efficacy during ethanol abstinence.

In the present study, a small dose ethanol $(0.8 \mathrm{~g} / \mathrm{kg}$, i.p.) administration (priming) following extinction trials significantly reinstated the motivation of subjects to reach the goal box. This result is in agreement with a previous study for "relapse" drinking in a two-bottle and in a four-bottle oral ethanol selfadministration paradigm[27]. According to the current analysis, $(5 \mathrm{~g} / \mathrm{kg}$, p.o.) of MMC and $(300 \mathrm{mg} / \mathrm{kg}$, p.o.) of the reference drug acamprosate were identified to be effective in turning back or relieving ethanolinduced restoration of runway behavior, which implies that MMC is likely to be effective only at $(5 \mathrm{~g} / \mathrm{kg}$, p.o.) in treating relapse of ethanol self-administration.

\section{CONCLUSION}

Overall, the current experimental data results reveal the anti-motivational properties of $M$. citrifolia fruit in subjects traversing the modified runway for self-administration of ethanol thereby suggesting the therapeutic potential of $M$. citrifolia fruit against alcohol dependence. Additional clinical investigations are required to confirm these preclinical findings.

\section{MATERIALS AND METHODS}

\subsection{Unripe M. citrifolia fruit extract}

Methanolic extract of M. citrifolia (MMC) was standardized first and then used for the present study and its preparation and phytochemical characterization was demonstrated in our earlier publications $[6,20]$.

\subsection{Animals}

All animals were weighed 25-30 g bw. Animals were housed and fed for 7 days earlier the initiation of the study. All the experiments were conducted as per guidelines set of University of Malaya (Approval No. 2013-12-03/PHAR/R/VP) to meet the standards of the National Research Council of the Academies of the USA.

\subsection{Drugs}

Ethanol $(10 \% \mathrm{v} / \mathrm{v})$ solution was acquired from ethanol (95\% v/v) (Copens Scientific, Malaysia) in sterile water for injection and injected into peritonium. MMC and ACAM suspension was prepared in $1 \%$ $\mathrm{w} / \mathrm{v}$ sodium carboxymethyl cellulose. In order to prepare MMC and ACAM suspensions $1 \% \mathrm{w} / \mathrm{v}$ sodium carboxymethyl cellulose was used and given by oral route in a constant amount of $1 \mathrm{ml} / 100 \mathrm{~g}$ body weight of the animal $1 \mathrm{~h}$ prior to postconditioning, extinction, and reinstatement tests.

\subsection{Modified Straight Alley Runway Paradigm of Ethanol Self-Administration in mice}

\subsubsection{Apparatus}

The Composite Aluminium was used to make this apparatus as described in our earlier publication [3]. The mice tracement using this apparatus was noted in real time with the help of a Logitech webcam (C270) mounted above the apparatus and also attached with a computer. Using a digital stopwatch, the run time (seconds) was assessed manually. 


\subsubsection{Procedure}

After 3 days of each 15 min habituation to the runway device (except the target box), the experimental data collection was initiated. On a given trial, every mouse was kept for testing in the initiation (start) box, and then permitted to traverse the alley and enter the goal box, the time required to do so (run time) was recorded on every trial and constituted the primary dependent measure. Following 3-day habituation, a baseline runtime was recorded which was served as preconditioning runtime. Conditioning/acquisition trials were then initiated for the next 5 days (Day 1-Day 5) during which each animal received ethanol (raising doses $0.5,1,2,4$ and $4 \mathrm{~g} / \mathrm{kg}$, i.p.) or saline upon entry into the goal box and conditioned for half an hour in the target (goal) box from Day 1 to Day 5 as described previously [3]. The Post-conditioning test was performed $24 \mathrm{~h}$ after the last conditioning (on Day 6) during which no saline or ethanol doses were given upon target box entry. From Day 7 to Day 11, animals were subjected to extinction trials during which animals did not receive ethanol or saline upon goal box entry. On Day 12 no procedures were performed, then on Day 13, the animals underwent reinstatement testing in which animals got a small dose of ethanol $0.8 \mathrm{~g} / \mathrm{kg}$, i.p. (1/5th of the maximum dose of ethanol used in conditioning) to reinstate the subjects' motivation to receive ethanol in the goal box.

\subsubsection{Effect of MMC and ACAM on ethanol seeking behavior in mouse runway paradigm of self-administration}

Mice were randomly selected and divided into six groups such as: Group 1- Saline control group; Group 2- Ethanol control group; Group 3, 4, 5- MMC (1, 3, and $5 \mathrm{~g} / \mathrm{kg}$, p.o.)-treated groups respectively; Group 6- a reference drug, acamprosate (ACAM) $(300 \mathrm{mg} / \mathrm{kg}$, p.o.)-treated group. During the conditioning stage, the saline-control group (Group 1) was administered with saline whereas Groups $(2,3,4,5$, and 6$)$ received ethanol upon goal box entry as depicted in Figure 4 . The test groups served with MMC $(1,3$, and 5 $\mathrm{g} / \mathrm{kg}$, p.o.) and ACAM (300 mg/kg, p.o.), $1 \mathrm{~h}$ prior to postconditioning, extinction, and reinstatement testing.

Data are expressed as mean \pm S.E.M. The results were analysed using two-way ANOVA with post hoc Bonferroni's multiple comparisons test for post conditioning and reinstatement results. A repeated measures analysis of variance (ANOVA) using one -between-subject's variable - Group and a -within-subject's variable -Trial was performed for the extinction trial results. Statistical significance was set as $p<0.05$.

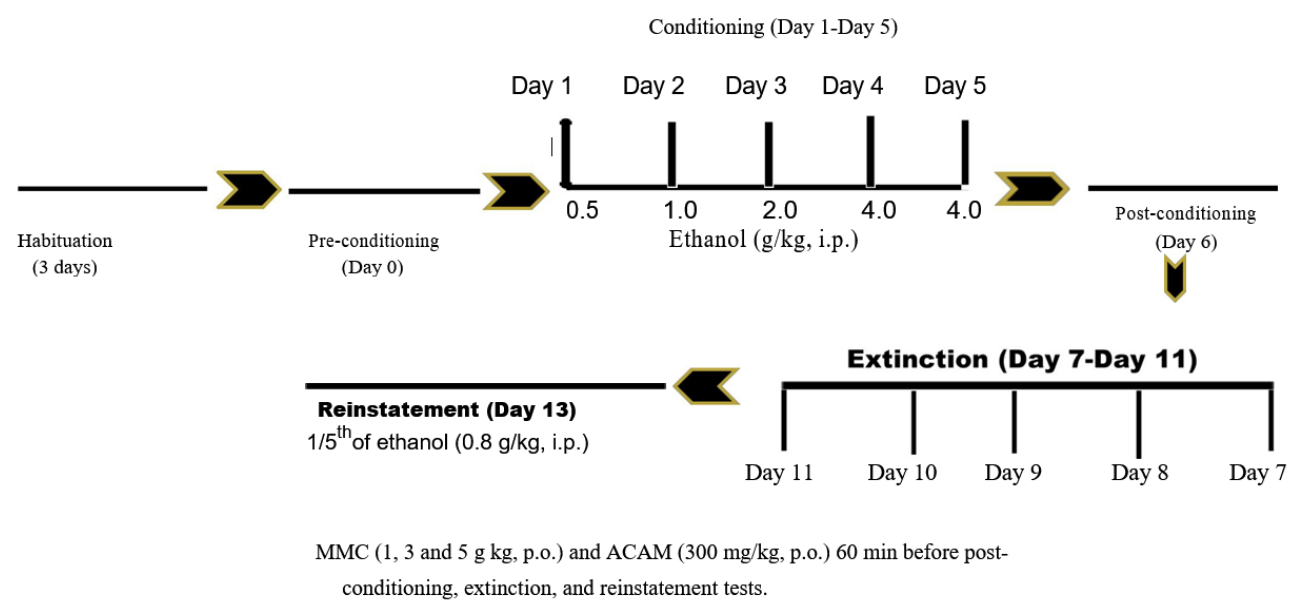

Figure 4. Study design of mouse runway paradigm of drug self-administration. 
Acknowledgements: The author V.P extend his sincere appreciation to Science \& Engineering Research Board (SERB), India for the core research grant (CRG/2018/000813).

Author contributions: Concept - Y.K., V.P.; Design - Y.K., V.P.; Resources - Y.K., V.P.; Materials - Y.K., V.P.; Data Collection and/or Processing - Y.K., V.P.; Analysis and/or Interpretation - Y.K., V.P.; Literature Search - Y.K., V.P.; Writing - Y.K., V.P.; Critical Reviews - Y.K., V.P.

Conflict of interest statement: The authors declare that they have no competing interests.

Ethics committee approval: This study was approved by FOM Institutional Animal Care and Use Committee, University of Malaya (FOM IACUC) with approval number 2013-12-03/PHAR/R/VP on December 18, 2013.

\section{REFERENCES}

[1] Ettenberg A. The runway model of drug self-administration. Pharmacol Biochem Behav. 2009; 91: $271-277$. [CrossRef]

[2] Geist TD, Ettenberg A. A simple method for studying intravenous drug reinforcement in a runway. Pharmacol Biochem Behav. 1990; 36: 703-706. [CrossRef]

[3] Pandy V, Khan Y. Design and development of a modified runway model of mouse drug self-administration. Sci Rep. 2016; 6, 21944. [CrossRef]

[4] Dixon AR, McMillen H, Etkin NL. Ferment this: the transformation of Noni, a traditional Polynesian medicine (Morinda citrifolia, Rubiaceae). Econ Bot. 1999; 53(1): 51-68. [CrossRef]

[5] Narasingam M, Vijeepallam K, Mohamed Z, Pandy V. Anxiolytic- and antidepressant-like activities of a methanolic extract of Morinda citrifolia Linn. (noni) fruit in mice: Involvement of benzodiazepine-GABA $A_{A}$ ergic, serotonergic and adrenergic systems. Biomed Pharmacother. 2017; 96: 944-952. [CrossRef]

[6] Pandy V, Narasingam M, Mohamed Z. Antipsychotic-like activity of Noni (Morinda citrifolia Linn.) in mice. BMC Complement Altern Med. 2012; 12(1): 186. [CrossRef]

[7] Narasingam M, Pandy V, Mohamed Z. Noni (Morinda citrifolia L.) fruit extract attenuates the rewarding effect of heroin in conditioned place preference but not withdrawal in rodents. Exp Anim. 2016; 65(2): 157-164. [CrossRef]

[8] Khan Y, Pandy V. Methanolic Extract of Morinda citrifolia L. (Noni) Unripe Fruit Attenuates Ethanol-Induced Conditioned Place Preferences in Mice. Front Pharmacol. 2016; 7: 352. [CrossRef]

[9] Pandy V, Wai YC, Roslan NFA, Sajat A, Jallb AHA, Vijeepallam K. Methanolic extract of Morinda citrifolia Linn. unripe fruit attenuates methamphetamine-induced conditioned place preferences in mice. Biomed Pharmacother. 2018; 107: 368-373. [CrossRef]

[10] Pandy V, Khan Y. Noni (Morinda citrifolia Linn.) fruit juice attenuates the rewarding effect of ethanol in conditioned place preference in mice. Exp Anim. 2016; 65(4): 437-445. [CrossRef]

[11] Issell BF, Franke A, Fielding RM. Pharmacokinetic study of Noni fruit extract. J Diet Suppl. 2008 ; 5: $373-382$. [CrossRef]

[12] Wang MY, West BJ, Jensen CJ, Nowicki D, Su C, Palu AK, Anderson G. Morinda citrifolia (Noni): a literature review and recent advances in Noni research. Acta Pharmacol. Sin. 2002; 23: 1127-1141.

[13] Yang YF, Wei Xu, Song W, Ye M, Yang XW. Transport of Twelve Coumarins From Angelicae Pubescentis Radix Across a MDCK-pHaMDR Cell Monolayer-An in Vitro Model for Blood-Brain Barrier Permeability. Molecules. 2015; 25: 20(7): 11719-32. [CrossRef]

[14] Zulissetiana KF, Susilawati. The Efficacy of Noni Fruit Methanol Extract (Morinda citrofolia) to Brain Derived Neurotrophic Factor (BDNF) on Male Swiss Webster Mice Induced By Immobilization Stress. Journal of Physics: Conf. Series 1095. 2018; 012013.

[15] Muralidharan P, Srikanth J. Anti epileptic activity of Morinda citrifolia Linn fruit extract. J Chem. 2010; 7: 612-616. [CrossRef]

[16] Schulte T, Oberlin BG, Kareken DA, Marinkovic K, Müller- Oehring EM, eyerhoff DJ, Tapert S. How acute and chronic alcohol consumption affects brain networks: insights from multimodal neuroimaging. Alcohol Clin Exp Res. 2012; 36(12): 2017-2027. [CrossRef]

[17] Luo SX, Huang EJ. Dopaminergic neurons and brain reward pathways: from neurogenesis to circuit assembly. Am J Clin Pathol. 2016; 186(3): 478-488. [CrossRef] 
[18] Aguilar MA, Manzanedo C, Do Couto BR, Rodríguez-Arias M, Miñarro J. Memantine blocks sensitization to the rewarding effects of morphine. Brain Res. 2009; 1288: 95-104. [CrossRef]

[19] Davis M, Myers KM. The role of glutamate and gamma-aminobutyric acid in fear extinction: clinical implications for exposure therapy. Biol Psychiatry. 2002; 52(10): 998-1007. [CrossRef]

[20] Pandy V, Narasingam M, Kunasegaran T, Murugan DD, Mohamed Z. Effect of noni (Morinda citrifolia Linn.) fruit and its bioactive principles scopoletin and rutin on rat vas deferens contractility: an ex vivo study. ScientificWorldJournal. 2014; 2014: 909586. [CrossRef]

[21] Pandy V, Narasingam M, Vijeepallam K, Mohan S, Mani V, Mohamed Z. The Ethyl Acetate Fraction of a Methanolic Extract of Unripe Noni (Morinda Citrifolia Linn.) Fruit Exhibits a Biphasic Effect on the Dopaminergic System in Mice. Exp Anim.2017; 5: 66(3): 283-291. [CrossRef]

[22] Pandy V, Vijeepallam K. Antipsychotic-like activity of scopoletin and rutin against the positive symptoms of schizophrenia in mouse models. Exp Anim. 2017; 66 (4): 417-423. [CrossRef]

[23] Bevins RA, Besheer J, Pickett KS. Nicotine-conditioned locomotor activity in rats: dopaminergic and gabaergic influences on conditioned expression. Pharmacol Biochem Behav. 2001; 68: 135-145. [CrossRef]

[24] Kuzmin A, Sandin J, Terenius L, Ogren SO. Acquisition, expression, and reinstatement of ethanol-induced conditioned place preference in mice: effects of opioid receptor-like 1 receptor agonists and naloxone. J Pharmacol Exp Ther. 2003; 304(1): 310-318. [CrossRef]

[25] Mattioli L, Titomanlio F, Perfumi M. Effects of a Rhodiola rosea L. extract on the acquisition, expression, extinction, and reinstatement of morphine- induced conditioned place preference in mice. Psychopharmacology (Berl). 2012; 221(2): 183-193. [CrossRef]

[26] Mueller D, Stewart J. Cocaine-induced conditioned place preference: reinstatement by priming injections of cocaine after extinction. Behav Brain Res. 2000; 115(1): 39-47. [CrossRef]

[27] Spanagel R, Hölter SM, Allingham K, Landgraf R, Zieglgänsberger W. Acamprosate and alcohol: I. Effects on alcohol intake following alcohol deprivation in the rat. Eur J Pharmacol. 1996; 305 (1-3): 39-44. [CrossRef]

This is an open access article which is publicly available on our journal's website under Institutional Repository at http://dspace.marmara.edu.tr. 